\title{
Quality of life of long wait orthopaedic patients before and after admission: a consumer audit
}

\author{
Marianne Rigge
}

This is the first article in an occasional series of papers describing health care services and health care quality from consumers' perspectives.

Involving patients and consumers in the planning and provision of health care is a welcome, though still somewhat novel, activity in the NHS. The NHS Management Executive has recognised the need for health authorities to develop their role as champion of consumers by consulting and involving them at every stage of the planning process. ${ }^{12}$

The College of Health is a national charity set up in 1983, whose aims include helping people to make the most effective use of the NHS, improving the quality of communication, and representing patients' interests to those who make decisions about how and when patients are treated. The college has pioneered the development of a range of research techniques to find out what patients think of, and want from, the services they receive - a process it has called consumer audit. ${ }^{3}$

Consumer audit seeks to avoid the "tick in the box" approach to measuring patient satisfaction. Research has shown that most patients will say they are very satisfied if asked to give an overall assessment of services they have received. ${ }^{4}$ Instead, the college uses patient centred techniques, including focus group discussions; observation; and in depth, semistructured interviews with patients and their carers in their own homes.

In April 1991 Worthing District Health Authority commissioned the college to carry out a study based on in depth interviews in the homes of up to 60 patients on the lists of its four consultant orthopaedic surgeons and waiting for hip or knee replacements. Worthing is one of the Department of Health's total quality management demonstration sites and is committed to making all its services "customer driven." In addition, a successful bid to the Waiting Time Initiative Fund in 1991-2 enabled Worthing to admit 1175 long wait elective surgery patients over and above those who would normally have been admitted. Four hundred and sixty of these patients had been waiting for admission for orthopaedic surgery.

The main purpose of this study was to find out the extent to which the quality of life of these orthopaedic patients had been affected by their long wait for admission and treatment and how much they felt they had benefited subsequently from their surgery.

\section{Patients and methods}

With the approval of the district ethics research committee, staff at Southlands Hospital initially wrote to 60 patients awaiting hip or knee replacements, all of whom would have been on the waiting list for at least two years by April 1992 if money from the Waiting Time Initiative Fund had not been made available. They asked the patients to inform the hospital if they would prefer not to be approached by a researcher from the College of Health with a view to being interviewed in their own homes before and after their operation. It subsequently proved necessary to write to a further 26 patients to achieve a revised sample size of 50 (see below).

The college was then sent a list of these patients, recording relevant details including the date they had been put on the waiting list.

\section{BEFORE ADMISSION}

Fifty patients were interviewed in their own homes at a time of their convenience. Semistructured interviews lasting between 20 minutes and two hours were carried out, during which patients were asked to say in their own words how their lives had been affected by their medical condition and the experience of waiting for admission to hospital (box). Twenty four patients were awaiting a knee replacement and 26 a hip replacement; 32 were women and 18 men.

\section{AFTER DISCHARGE}

The college was notified of the date of discharge of the patients on the list, and when possible, patients were interviewed in their own homes again with the same method. Interviews were held at least six weeks subsequently, and in some cases several months subsequently. Seventeen of the original 50 patients were unable to be interviewed after discharge: six had still not been admitted, four had been suspended from the list because they were not ready for surgery, three were too unwell or had to care for spouses who were ill, three preferred not to be interviewed again (because they felt they had been through enough or were just too busy), and one had already had the operation privately at the time of the first 


\section{Interview topics}

\section{Before admission}

Waiting time before general practitioner decided to refer

Waiting time for outpatient consultation

Information about likely waiting time for admission

Effects on work (when appropriate)

Effects on day to day activities and mobility

Effects on family and social life, including

hobbies and holidays

Effects of pain and what patients take or do for it

Ability to sleep

Aids and adaptations and where obtained

Information patients have had from hospital or would like

What patients are hoping for from the operation

\section{After discharge}

Notice given of admission

Check up before admission

Admission procedure

Information and explanation/consent, etc

Anaesthetic

Postoperative pain and recovery

Physiotherapy and occupational therapy

Nursing care and information

Medical care and information

Hotel aspects - bathrooms

Visiting hours

$$
\text { - food }
$$

Discharge arrangements

Aids and adaptations/social services

General practitioner, community nurse services, etc

Postoperative appointment

Patient's view of outcomes

interview. The study covered the views of 33 patients about their experience in hospital and a full report is available $e^{5}$; this article reports patients' views of their experience before and after their admission.

\section{Results}

VALIDATION PROCEDURE FOR HOSPITAL

WAITING LIST

Despite all the attention drawn to the need to validate hospital waiting lists, for example, to ensure that they do not include "ghost" patients, of the 86 patients thought by the hospital to be on the waiting list, 18 had in fact already had their operation, most at the hospital concerned, ${ }^{6}$ two had had their operations at other NHS hospitals and two privately, 10 patients were no longer well enough to have their operation, three had died, and one patient could not be contacted by telephone or letter.

The information recorded for patients was not always accurate or complete. In several instances, names or addresses were incorrect and for several patients their telephone numbers were not recorded or were exdirectory, thus making it more difficult to arrange interviews.

WAITING TIME

Although most of the patients interviewed had been on the official waiting list for two years or less, many of them had been having problems for much longer. For some patients, the time between first asking the general practitioner for a referral and finally being treated was more than five years. The worst thing for others was having no idea how long even the "official" wait would be. Several patients had been given false hopes, being led to believe that the wait might be six to 12 months, when it was in fact two years or more.

\section{PRIVATE TREATMENT}

Some patients had paid for private outpatient consultations or treatment, even though they could ill afford it.

$\mathrm{Mr}$ Tolley had, with some reluctance, paid to see the consultant privately because his general practitioner had said that the waiting time for an outpatient appointment was so long that he might be in a wheelchair before he was seen. (He had to use crutches and a wheelchair at the time of the first interview.) He had been told in early 1990 that he might have to wait six months for admission on the NHS. But when his sister rang the consultant's secretary after 12 months had elapsed to find out whether it would be safe to go on holiday, she had said, "Oh, you saw him privately, didn't you?" and $\mathrm{Mr}$ Tolley and his sister thought that must mean that they had put a black mark against him.

\section{COPING WITH PAIN}

No patient interviewed in the study was without pain, and for some patients pain affected the quality of their life more than anything else.

"The pain is just hell. I can think of nothing but pain. It's ruining my life. My thoughts are just with pain."

People's attitude to pain and what they did about it varied considerably. At one extreme were the patients who took a minimalist, even a nihilist, approach, who despite being in pain and being prescribed painkillers by their general practitioner preferred not to take them. At the other were patients who had been taking up to and even over the maximum dosage of strong analgesics, including one man who had "cut down" to 10 co-codamol a day because "other things have done terrible things to my insides over the years," and a women who was "officially" taking three ibuprofen a day but as these did not help much was also getting distalgesic from her sister and co-proxamol from her grandson. Her general practitioner did not know this because she didn't like to tell him.

In between were people who had had to resort to non-drug methods of pain relief because they had other conditions such as ulcers or hiatus hernias which meant that they could not take analgesics. The NHS had done little to help such patients. Not one of the 50 interviewed while they were waiting for admission had been referred to a pain clinic. Only one woman, who had a perforated ulcer, had been referred for hydrotherapy within the NHS. Having had nine sessions two years previously and found the treatment very helpful, she had been told that she had had her quota and could not have any more treatment. 
At the time of the interviews she was having one private hydrotherapy session a week, which was all she could afford. Access to other non-drug methods of coping with pain, such as physiotherapy, was similarly limited.

\section{MOBILITY}

The ability to pursue day to day activities that most people take for granted was a major hurdle for many patients in the study. Unfortunately, for some patients the onset of their hip or knee problem coincided with the death or illness of a spouse on whom they had previously relied to use a car. Others had been prevented from driving themselves by their condition.

Several patients commented on the difficulties of using public transport - high steps on to buses and trains and steep flights of stairs at stations made it impossible for some people to travel on either modes of transport and left them highly dependent on family, friends, or neighbours to go anywhere. Some patients were completely housebound.

LOSS OF DIGNITY

Some patients tried to make light of the fact that their gait was so badly affected by their joint condition that they looked ungainly or even drunk, or had to rely on complete outsiders for such intimate activities as bathing.

"You don't like to be undressed by every

Tom, Dick, and Harry. After all, I'm not a pretty fine figure any more. I call myself 'the hanging gardens." "

Several patients reported on the fright as well as indignity they had suffered when they had fallen. Two had hurt themselves badly in the process and had spent time in hospital as a result.

EFFECTS ON FAMILY LIFE

Many patients were trying to look after spouses with even more invalidity and the worry that this caused was considerable, especially worry about what would happen to the spouse during the patient's time in hospital and during convalescence. Other felt that they were a burden on children or other relatives on whom they had to rely far more than they would have wished as their relatives had busy lives of their own. For this reason some did not even ask for much needed help.

Several people commented on how being in constant pain makes you bad tempered with people you love, thus destroying the quality of life at a time when people might expect to enjoy being together in retirement.

BEING ALONE

Twenty three of the fifty patients interviewed before admission lived on their own, and many found this very difficult to cope with, both practically and emotionally, because their medical condition meant that there was much they were unable to do for themselves.

\section{FINANCIAL EFFECTS}

Most of the patients were retired and so were not adversely affected in terms of their earning capacity. However, one in eight had had to give up work because of their medical condition. A few were still hoping to return to work, if only to obtain a full pension on retirement, but this depended on whether they could have their operation before their allowable sick leave expired, a factor which their consultants were doubtless unaware of.

One man had spent so much money trying to keep mobile - over $£ 1000$ on an electric wheelchair and $£ 16000$ on a large van to put it in - that he would have been able to pay for a private operation several times over, had he thought about it in time.

\section{LEISURE ACTIVITIES}

The quality of many people's lives was greatly diminished by their being unable to pursue hobbies and other leisure activities. Chief among these were gardening, cycling, and walking.

"The worst thing is that I can't garden. It was the love of my life. I used to walk a lot as well - all over the hills."

AIDS AND ADAPTATIONS

One of the most striking findings of this study was the extent to which the provision of aids and adaptations to make daily living more comfortable and convenient seemed to be entirely haphazard. Patients who had received most help tended to be those who had already had orthopaedic surgery, and therefore knew what was available, or those who were persistent enough to contact the social services department on their own account. A few had had to spend much money to get the type of help which some others had obtained free.

INFORMATION FROM THE HOSPITAL

The main information most patients would have liked was about how soon they would be admitted. Few, if any, were told this. Several patients would really have appreciated, and probably greatly benefited from, information about how to get themselves as fit as possible for the operation - for example, information about exercise and diet - and patients who had physiotherapy after surgery commented on how much it would have helped if they had had this before as well. Several patients would also have appreciated being given information about convalescent care, either for themselves after the operation or as respite care for invalid spouses during their stay in hospital, which was particularly important in view of the short notice of admission usually given.

HOLIDAYS

Many patients had been unable to go on holiday, sometimes for two years running, because they feared they might miss their chance of admission. Some had lost considerable sums paid in deposits for holidays but had still not been admitted, despite having cancelled their holiday.

NOTICE OF ADMISSION

The case of one patient highlighted the inadequacy of the system for deciding who to 
call for admission when. In this case the hospital rang a neighbour (the patient did not have a telephone) while the patient was out shopping to see whether she could be admitted immediately. As she was not back by $11.00 \mathrm{am}$ the bed was given to someone else; over a year later, she was still waiting, having heard nothing more.

\section{ADMISSION}

Most patients were grateful to know that they were, at last going to be admitted, even if they were given very short notice of admission. A few, however, had problems, especially those who had to make arrangements for relatives with invalidity or pets to be looked after or had to book themselves into a convalescent home.

\section{ARRANGEMENTS FOR DISCHARGE}

The arrangements for providing aids and adaptations and for home helps and other social services seemed to be haphazard, as for patients before admission; however, most patients did obtain some help eventually.

"That was the final straw. Everything's on a bloody waiting list. I've been on a waiting list for a shower since last June." (Patient interviewed in December.)

POSTOPERATIVE APPOINTMENT

Several patients expressed disappointment that they had not seen their consultant at the postoperative appointment, that the junior doctors had not examined them thoroughly enough, or that they could not answer their questions. Several were told not to worry about problems with their recovery but were offered no follow up appointment, and they remained worried.

PATIENTS' VIEWS OF OUTCOMES

Just under a third of the 33 patients for whom a second interview was possible had had a postoperative complication, including septicaemia, an infection followed by a severe reaction to the antibiotics given, a fall leading to a dislocation on the first postoperative day, a deep vein thrombosis, and a severe pressure sore on the heel. Several other patients had complications which were not directly related to their orthopaedic surgery but nevertheless affected their recovery and their view of the outcome.

At least five of the patients inteviewed postoperatively were still very unhappy about the outcome of their operation several months after their discharge. Some felt bitter, although they did not blame the surgeon, and thought that things might have been different if they had not had to wait three years or more for the operation. One patient's worst fears came true when he had to go into a nursing home, and another patient dreaded the prospect of a much needed second joint replacement because he had developed septicaemia after the first.

Most patients, however, reported their gratitude at being freed from pain after so many years and at being able to walk without sticks or, at any rate, with much less difficulty than before.

"It's a little thing to say that you don't need sticks. But after all those years, twelve years, you feel different about everything. You see people out in the street who can't walk properly and you think 'poor souls' if only I could win the pools and buy them all an operation."

Many patients were able to report a dramatic reduction in the number of painkillers they were having to take, and some had been able to stop them altogether. Renewed mobility and freedom from pain literally transformed the quality of some patients' lives:

"I walk miles. We drive up to the Downs and we just walk. I'm reborn since the operation - I've no pain at all."

"There are so many people a lot worse than me. It's frustrating when you just want to get on with your life but you can't afford thousands of pounds to have it done. I'm so grateful I went in when I did. It's a really happy ending."

\section{Discussion}

The patients' main problem, recognised by the health authority and the hospital from the start, was the waiting time for the operation, and one crucial factor, which was recognised by many of the patients, was the amount of money available to develop appropriate services in a district with the highest proportion of elderly people in its population of any district in Britain.

This study highlighted problems related to validation and management of waiting lists. That 18 out of 86 patients on the waiting list had in fact already had their operation, most at the same hospital, is an astonishing indictment of the system. Inaccurate details and the lack of telephone numbers for patients whose numbers were ex-directory must also have implications for waiting list management, especially in an admissions system that seems to rely heavily on use of the telephone. The system also gave rise to much avoidable distress - for example, to those patients who cancelled holidays two years running or did not dare to go away so as to remain available for admission. The case of the woman who did not receive a telephone call from the hospital for over a year, having missed the initial call to arrange admision, and the attitude of staff towards the man who had paid for a private outpatient consultation on his general practitioner's advice, seem to confirm a suggestion that admissions staff may use unacceptable moralistic judgments. ${ }^{7}$

The haphazard nature of provision of social services both before and after admission shows that much improvement is needed before patients can reasonably expect "seamless" care.

The present method of collecting national statistics of waiting times disguises the fact that the actual waiting time is often very much longer than the time between seeing the consultant in the outpatient department and 
admission for surgery, and it may have clinical implications. At least one study has pointed to the very high success rates now being achieved with knee replacements but also pointed out that delaying the operation reduces the chance of success. ${ }^{8}$

The experience of several patients in this study also illustrates how consultants may remain unaware that patients are left feeling that they had had an unacceptable outcome. Under the present system junior doctors conducting postoperative follow up consultations at six weeks may sign patients off and record a satisfactory outcome in the medical records when this is not necessarily the case.

\section{Conclusions}

The study produced many practical suggestions about how the situation could be improved for patients who may still be faced with long waits in the future, despite the patient's charter and the new target of a maximum of 18 months' waiting time for admission after an outpatient consultation with the consultant.

Recommendations made by the College of Health covered many aspects of the patients' well being and care, recognising that the action needed to meet these did not lie solely with the health authority, which commissioned the study, nor with the hospital. It was clear from what the patients said about their experience while actually in hospital that there are many excellent and caring staff, and most patients were deeply appreciative of and grateful for the care they received. But a main conclusion was that if the same sort of patient centred care could be practised during the waiting time, as well as after discharge, the quality of life could be greatly improved.

The study clearly showed that there is need for much better communication between all the different partners in providing and caring for people disabled by degenerative disorders of the bones and joint. These include local authorities, especially their social services and transport departments; primary and community health service teams; physiotheraphy and occupational therapy staff; pharmacologists and others interested in pain relief; medical records staff; hospital social workers; dietitians; consultants' secretaries; and many others.

Patients could be offered a range of information and support. There could be agreed protocols between the hospital medical staff and community and primary health care teams about how life could be improved for people who are disabled and in pain so that they are as fit as possible for the operation as well as after discharge. In any case, as this study also showed, some patients will prove not to be fit for an operation at all, and for them the care they receive will affect the quality of the rest of their lives.

Responding to the report which he commissioned, Alan Randall, chief executive of Worthing and Southlands Hospitals, said:

"There is much in the feedback that speaks volumes for the high quality of care delivered by the Southlands Orthopaedic Department. Nevertheless, staff there could be forgiven for regretting having commissioned the study. It has unearthed a long list of areas needing action. To their credit, staff have welcomed the results, criticisms included. As a demonstration of their commitment to constant improvement, they have begun tackling the criticisms. There will be few instant solutions, but the study has been invaluable in revealing how much has yet to be done before patients can truly be said to be at the centre of hospital services."

The patients involved in this study spoke frankly to the researchers in the knowledge that the health authority and the hospital wanted to use the information they were able to give to improve services both for them and for other patients in the future. The College of Health and Worthing District Health Authority hope that similar patients elsewhere and the people who care for them might also benefit.

1 NHS Management Executive. Local voices: the views of local people in purchasing for health. London: HMSO, 1992.

2 Rigge M. Involving patients and consumers. Health management guide supplement. Health Service fournal 9 management

3 College of Health. Consumer audit guidelines. London: College of Health, 1994

4 Locker D, Dunt D. Theoretical and methodological issues in sociological studies of consumer satisfaction with medical care. Soc Sci Med 1989;12:283-92.

5 Rigge $M$. The quality of life of long-wait orthopaedic patients before and after admission to hospital. London: College of Health, 1993.

6 Yates J. Why are we waiting? Oxford: Oxford University Press, 1987.

7 Pope C. Trouble in store: some thoughts on the management of waiting lists. Sociology of Health and Illness management of waitir

8 Spector TD, Hart DJ. How serious is knee osteoarthritis? Ann Rheum Dis 1992;51:1105-6. 